\title{
Research on Several Experimental Modes of Electrical and Electronic Experiment Course
}

\author{
Hongmei Zhang \\ College of Mobile Telecommunications Chongqing University of Posts and Telecom
}

Keywords: Electrical and electronic; Experimental course teaching; Experimental mode

\begin{abstract}
. from the construction and planning, virtual experiment model of experimental pattern construction, environmental protection and construction of experimental model of innovative experimental building aspects in detail, this article gives better guide and improvement on the electrical and electronic professional teaching work to improve the overall quality of experimental teaching.

In twenty-first Century, with China's accelerating pace of the modernization, our country goes toward to innovation oriented society, economical society and environment protection and social development, for the modernization of teaching and also puts forward new requirements. Taking the electrical and electronic course as the main teaching breakthrough point as an example, the experiment teaching has been endowed with many requirements and planning, such as innovation, virtuality and environmental protection practice. In order to better construct the electrical and electronic experiment course, and understand the multi-level and multiform experimental curriculum construction system of college students, we must first understand the construction and planning requirements of the current experimental mode.
\end{abstract}

\section{Part One Construction and planning of experimental model}

With the employers in China for the talents of electrical and electronic technology professional practice ability and innovation consciousness of the increasing demand, coupled with the experimental course of electrical and electronic courses in the current construction and improve the level of the current common mode, and teaching planning in electrical and electronic experiment has become the core and key to realize comprehensive upgrade of professional teaching.

As one of the basic experimental courses of electrical and electronic professional, electrical and electronic experimental courses require students not only in the course of process smoothly master all kinds of basic knowledge and information technology hardware, but also requires students to master the ideas and methods for the analysis, so as to better finish the hardware circuit design, calculation and analysis. And further in-depth study of professional knowledge and framework structure, so as to better engage in electronic, telecommunications and other professional and technical fields of practical work to realize personal value and life planning and enhance the quality of life. [1] Many schools through the construction of training base of electronic professional form by the connection of the curriculum system and other related types of professional courses to enhance the experimental model of the construction level, and these ways have made good gains.

With the progress and development of era, the electrical and electronic professional courses in higher education not only abandon the original concept of traditional teaching, pay attention to people-oriented teaching ideas, and the more important is the cultivation of students' abilities as the core and focus of the teaching in the future, by strengthening the engineering practice consciousness and ability of students to promote the all-round development of students, this is not only the comprehensive quality, social construction and the development of globalization demands, it would help students to realize their own value, enhance the quality of employment which also has an important role.

\section{Part Three Virtual experiment mode}


The characteristic of virtual experiment is that the learning form is flexible and diverse, and it has stronger student adaptability and teaching pertinence. To carry out the virtual experiment teaching mode, schools should pay attention to the following aspects.

Topic design. As the key link to realize the virtual experiment teaching, the design and selection of the subject must be carried out in accordance with the nature and requirements of the experiment. In general, we divide the virtual experiment of electrical and electronic specialty into four different types, including basic type experiment, design type experiment, comprehensive experiment and creative experiment. [2] The basic experiment teaching mainly rely on EDA software, pays attention to the fundamental ability of experiment and experimental skills of the students which will provide reference procedures according to the requirements, and design and integrated type experiments that are relatively difficult requiring students to have knowledge of experimental design and certain professional basis to design among them, and comprehensive type of experiment often has strong practicality, the more inclined to solve practical problems in the work. Creative experiment requires students to fully grasp the above several types of experimental conditions, through their own understanding and knowledge of the professional to sort out the situation, putting forward to meet the needs of some experimental subject, which can be derived from other experimental results and can also be based on the theory summary question.

Selection of experimental methods. The characteristics of virtual experiment is that it has strong freedom and inclusiveness, which is the most abundant in the choice of experimental methods. In the virtual experimental teaching, the students can be different according to the actual experimental subject to their own learning, which not only improve the pertinence, but also a fundamental change to the original one class that can only choose a mode of experiment. In addition, about the experimental time and place, students can according to their actual learning needs and habits for independent choice, as long as the school allows the use of open laboratory that can arrange the time. Finally, the experimental model group, because the virtual experiment has strong pertinence, it is often with similar interest for students to choose, so the group also has more freedom, and independent group can also discuss through extracurricular learning ways to enhance the communication links to better mobilize the initiative students.

Assessment means. The evaluation of virtual experiment also has strong pertinence, which can be chosen by the students themselves. The exam includes hardware and software use level, comprehensive use of knowledge ability and so on, the difficulty can be freely selected according to the stages of learning of students, so as to fully reflect the effectiveness of the assessment to avoid unfair problems brought by the unified assessment.

\section{Part Three Environmental Protection Experiment Mode}

Social background of experimental model. With the continuous improvement of China's environment-friendly society construction, the current sustainable development as China's basic national policy, its application universality in all walks of life are increasing. As the electronics industry, due to the need to use something that lead pollution with strong nature of the metal, so in the actual application process, it must be carried out environmental screening by the green production and management mode to better protect the environment. [3] This is not only the demand of social construction and development, but also the objective requirement of the industry to achieve sustainable development. From the laboratory point of view, due to the traditional teaching mode will produce a large number of consumables and electronic waste, so it will cause a certain degree of pollution which causes the state and the government's attaches.

Connotation of environmental protection experiment mode.. The environmental protection mode has no experimental flow fixed, it is just a kind of pursuit of high efficiency with low cost experimental strategy, and students are required to have the full use of laboratory equipment and supplies the existing conditions with the ability to effectively carry out various experiments. For example, the use of computer simulation experiments to replace some of the more serious pollution laboratory experiments, so as to enhance the efficiency and effectiveness of the experiment, but it can protect the environment. 


\section{Part Four Innovative Experiment Mode}

Features of topic. The most important content of the experimental model with innovation as its main feature is the innovation of the experiment. In the innovative experiment mode, it must follow the principles and requirements of the following topics:

Firstly, maintain good creativity. The selection of topics plays an important role in stimulating students' experimental participation and enhancing the experimental process experience. The topic should be as close as possible to the daily classroom learning of students, to mobilize students' experimental positive subjectivity, enhance knowledge innovation consciousness and inquiry ability, so as to better play the function of innovation experiment.

Secondly, pay attention to the adaptability of topic selection. Despite the innovative experiment mode on the surface that is a kind of inquiry process, but considering the students in the experimental classes for professional curriculum knowledge is relatively limited, so choosing process or to objective capacity needs comprehensive consideration of students, not too much attention to the degree of novelty problem leading to difficulties in the process of many students who are even unable to complete the delivery of the task, the confidence will have serious impact on the students, there is no good effect to reflect the advantages of innovation experiment.

Thirdly, it has good continuity. Continuity is the important topic of the principle of innovation experiment, the requirements after completion of the experiment can guide students to continue to extend through the way to carry out independent research, function and value innovation experiment.

Guiding strategy. The key of innovation experiment lies in relationship processing. In the experimental course of traditional teaching, in order to improve the efficiency of classroom teaching, most of the teachers will take the teaching way, but it will definitely give students the impression lead to innovation first impressions, the effect of experiment course can not be fully revealed. [4] On the contrary, in the teaching process, if students can establish innovation consciousness through good guidance to change the traditional concept and behavior mode, not only can better play the role of students in teaching activities, helps students and builds more democratic relationship between teachers and students, so as to stimulate students' learning enthusiasm with the desire to develop the practical ability and innovative operating habits, for the future development of innovative personality, it also has an important influence. In addition, the most important thing is to pay attention to the result and induction of experiment in the teaching of innovative experiment. This is because the innovation experiment itself is a process of inquiry which has a high rate of failure, but failure does not mean that there is no harvest, as long as through the careful induction and summary to understand the causes of failure analysis and improvement measures, and it can strengthen the students' experimental ability, to enhance students' professional learning confidence and perceived comprehension with some help.

National environmental analysis. With the comprehensive national strength between countries in recent years for the transformation from the original resource competition which has gradually become the competition of talent and innovation, and the innovation experiment is a core part of the construction and development of the international academic, its position in the teaching in Colleges and universities in our country also has improved significantly. Many colleges have established the innovation lab through cooperation with enterprises of the current implementation of the school enterprise cooperation mode, it effectively promotes the combination of research and extension, and the professional quality of personnel training has more international characteristics to enhance the overall competitiveness of China's academic field that also has an important influence. It believes that with the introduction of relevant national policies continue, the future will also serve as the innovative teaching mode in Colleges and universities of China related professional core mode of teaching, research and academic construction has been widely used in various fields providing technical support and guarantee for the sustained development of China's modernization. 


\section{Conclusion}

To sum up, as an important guarantee of realizing teaching quality of electronic professional electronic comprehensive promotion, construction of experimental curriculum should not only adapt to social development, but also as far as possible to inherit and carries forward the advanced education idea, as soon as possible to update teaching concepts through the way of time and advance the combination of the gradual improvement of experimental teaching reform. According to these requirements, this article separately from the three different modes of teaching the angle of effective elaboration, also hopes that through this guide more teachers pay more attention to the experimental teaching reform, the research and application of experimental teaching methods enhance students' practical ability, in fact, as a contribution to the realization of national construction and development of new power.

\section{Reference}

[1] Mingshan Cai.Research and design of university laboratory integrated management system[D]. Hunan University,2003.

[2] Guihong Zhou.Design of virtual electrical and electronic experiment system of Higher Vocational Education Based on Ulteo[D].South China University of Technology,2016.

[3] Nannan Cheng.Development and research of virtual electrical and electronic experiment operation system on Internet[D].North China University of Technology,2007.

[4] Chengzhi Zhu.Integration of information technology and electronic experiment course[D].Hunan University of Science and Technology,2007. 